\title{
Takotsubo Syndrome in the Context of Transmural Acute Myocardial Infarction: Prevalence and How to Differentiate?
}

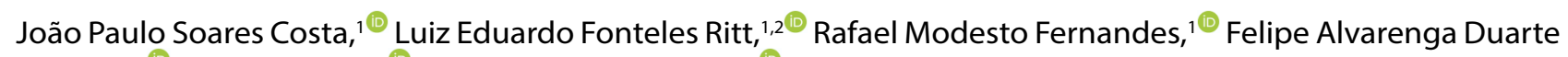
Campos, $^{1 \oplus}$ Queila Borges, ${ }^{2}{ }^{\circledR}$ Eduardo Sahade Darzét,2@

Escola Bahiana de Medicina e Saúde Pública,' Salvador, BA - Brazil

Hospital Cárdio Pulmonar, ${ }^{2}$ Salvador, BA - Brazil

Takotsubo syndrome (TTS) is characterized by acute and reversible cardiac dysfunction. Because of clinical similarities between TTS and acute coronary syndrome, their differential diagnosis is a challenge.

To describe the prevalence of TTS among patients suspected of ST-elevation myocardial infarction (STEMI) and compare the clinical profile of TTS with that of STEMI.

A retrospective analysis of medical records was performed on patients diagnosed with TTS with ST elevation (cases) and patients diagnosed with STEMI (controls) at Cárdio Pulmonar Hospital, Bahia, Brazil, between 2011 and 2017. For each case, four controls were randomly selected. Categorical data were compared using Pearson's chi-square and Mann-Whitney tests.

Six patients had a confirmed diagnosis of TTS, corresponding to $3.2 \%$ of the patients suspected of STEMI. All TTS cases were female; ejection fraction was lower in TTS than in STEMI (35.5 vs. $56.0 \%$; $\mathrm{p}=0.018$ ); patients with STEMI had higher peak troponin levels (9.4 vs. $2.2 \mathrm{ng} / \mathrm{mL}$; $\mathrm{p}=0.033$ ), and neuropsychiatric disorders were more common in the TTS group (50.0 vs. $12.5 \% ; \mathrm{p}=0.04)$. The median InterTAK diagnostic score was 60.5 (interquartile range 43.067 .0 ) in cases and 24 (interquartile range 18.0-39.5) in controls $(\mathrm{p}<0.001)$.

\section{Keywords}

ST Elevation Myocardial Infarction; Takotsubo Cardiomyopathy; Stress, Psychological; Stress, Physiological; Ventricular Function Left; Acute Coronary Syndrome/diagnosis.
TTS differed from STEMI in that it was more prevalent in females and was associated with emotional or physical stress, neuropsychiatric disorders, lower ejection fraction, and lower peak troponin levels.

\section{Introduction}

Takotsubo syndrome (TTS) is characterized by transient left ventricular dysfunction culminating in acute cardiac dysfunction. It is frequently preceded by emotional or physical stress. ${ }^{1,2}$

The most common symptoms at presentation are chest pain and dyspnea. Because the presentation of TTS is similar to that of acute coronary syndrome (ACS), the differential diagnosis is difficult, especially from ST-elevation myocardial infarction (STEMI). Absence of coronary artery disease in the affected area must be confirmed to establish the diagnosis of TTS. ${ }^{2}$ To facilitate the diagnosis of TTS, the European Society of Cardiology has recently developed the InterTAK diagnostic score, a promising tool that estimates the probability of a TTS event. ${ }^{3,4}$

The aim of this study was to analyze the prevalence of TTS among patients suspected of STEMI and to compare the clinical profiles of TTS and STEMI patients.

\section{Methods}

\section{Study design and sample}

This was a nested case-control study. We evaluated the medical records of patients with ST-elevation ACS admitted to Cárdio Pulmonar Hospital, Salvador, BA, Brazil, between 2011 and 2017, who received a final diagnosis of TTS (cases) or STEMI (controls). For each case, four controls were randomly selected. 


\section{Inclusion criteria}

Patients with ST-elevation and suspicion of ACS at admission, who were subsequently diagnosed with TTS according to Mayo Clinic criteria, ${ }^{5}$ were included in the case group.

Patients with ST-elevation and suspicion of ACS at admission, who were subsequently diagnosed with STEMI according to the Universal Definition of Myocardial Infarction, ${ }^{6}$ were included in the control group.

\section{Exclusion criteria}

Patients with a previous diagnosis of heart failure, those without coronary angiography, and patients with cardiorespiratory arrest at admission were excluded from the study.

\section{Statistical analysis}

Normally distributed continuous variables are described as mean \pm standard deviation (SD), and nonnormally distributed continuous variables are expressed as median and interquartile range (IQR). Categorical variables are presented as percentages. The Student's t-test (parametric) or the Mann-Whitney test (nonparametric) was used for comparison of continuous variables. Categorical variables were compared using Pearson's chi-square test and or the Fisher's exact test when appropriate. A value of $\mathrm{p}<0.05$ was considered to denote statistical significance.

\section{Ethical aspects}

The project was approved by the Research Ethics Committee of Santa Izabel Hospital (CAAE no. 76922117.0.0000.5520). Written informed consent was not required given the retrospective nature of the study.

\section{Results}

We evaluated 183 cases of suspected STEMI, six (3.2\%) of them diagnosed with TTS. Comparison of demographic and clinical variables between cases and controls is shown in Table 1.

TTS patients had a higher frequency of previous emotional stress (50.0 vs. $12.5 \%$; $p=0.04$ ), higher prevalence of depressive disorders ( 50.0 vs. $12.5 \%$; $\mathrm{p}=0.04$ ), lower peak troponin levels (2.20 vs. $9.43 \mathrm{ng} /$ $\mathrm{mL} ; \mathrm{p}=0.033)$, lower ejection fraction ( 35.5 vs. $56.0 \%$; $\mathrm{p}=0.018)$, and longer QTc intervals (516ms vs. 452 $\mathrm{ms} ; \mathrm{p}=0.01$ ) than STEMI patients. Also, TTS patients had significantly higher InterTAK scores (60.5 vs. 24.0; $\mathrm{p}<0.001$ ), figure 1 .

\section{Discussion}

The data presented in this study, on a population of patients suspected of STEMI in Brazil, are in agreement with the literature and large multinational registries. ${ }^{1,2}$ The prevalence of TTS (3.2\%) was higher than that reported in other studies, probably because the study population was composed only of suspected cases of STEMI.

Most international Takotsubo registries ${ }^{2,3}$ have collected data on patients with clinical manifestations of ACS, including STEMI and non-STEMI patients. Our study focused exclusively on patients within the spectrum of STEMI, because the need for a rapid diagnosis and rapid initiation of reperfusion therapy in STEMI cases makes the differential diagnosis from TTS a challenge. Early recognition of TTS can help avoid unnecessary procedures in these patients.

Among the variables that differed significantly between cases and controls, we highlight gender, emotional and/or physical stress, neuropsychiatric disorders, and prolonged QTc interval - all of them compose the InterTAK score, a diagnostic tool that estimates the probability of a TTS event, with good sensitivity and specificity. ${ }^{3}$ Although each of these characteristics is not specific of TTS, when taken together, they strongly suggest TTS. ${ }^{2}$ There was a high prevalence of coronary artery disease (50\%) in the TTS group, which was not associated with left ventricular dysfunction. This prevalence was higher than that reported in international registries and may be related to the mean age of the case group (72.5 \pm 7.2 years). In this age range, some degree of coronary atherosclerosis is expected.

A recent expert consensus statement on TTS $^{7}$ recommended the use of the InterTAK score only for patients suspected of TTS with non-ST elevation ACS. However, the good performance of the tool in our study suggests that it may also be used in suspected cases of STEMI, as sometimes the coronary pattern alone is not sufficient to differentiate between myocardial infarction with normal coronary arteries, myocarditis, and TTS, even in the absence of coronary obstruction.

The limitations of our study include its retrospective nature and the lack of a clinical follow-up. The small 
Table 1 - Comparison of demographic and clinical variables between patients diagnosed with Takotsubo syndrome and acute myocardial infarction*

\begin{tabular}{|c|c|c|c|}
\hline Characteristic & Takotsubo syndrome $(\mathrm{n}=6)$ & Acute myocardial infarction $(n=24)$ & $p$ value + \\
\hline Age, years & $72.5 \pm 7.2$ & $65.3 \pm 13.3$ & 0.109 \\
\hline Female, $\mathrm{n}(\%)$ & $6(100 \%)$ & $8(33.3 \%)$ & 0.003 \\
\hline Isolated chest pain, $\mathrm{n}(\%)$ & $2(33.3 \%)$ & $14(58.3 \%)$ & 0.025 \\
\hline Emotional and/or physical stress, $\mathrm{n}(\%)$ & $3(50.0)$ & $3(12.5 \%)$ & 0.040 \\
\hline InterTAK score & $60.5(43.0-67.0)$ & $24.0(18.0-39.5)$ & $<0.001$ \\
\hline Heart rate, bpm & $74(68-84)$ & $74(65-83)$ & 0.667 \\
\hline Systolic blood pressure, $\mathrm{mmHg}$ & $128(113-145)$ & $140(112-158)$ & 0.672 \\
\hline Body mass index, $\mathrm{kg} / \mathrm{m}^{2}$ & $22.85(21.9-27.1)$ & $28.40(24.9-29.4)$ & 0.050 \\
\hline QTc interval, ms & $516.5(475.0-550.0)$ & $452(429.0-468.5)$ & 0.010 \\
\hline Peak troponin value, $\mathrm{ng} / \mathrm{mL}$ & $2.2(0.69-3.66)$ & $9.43(3.19-30.00)$ & 0.033 \\
\hline Peak CK-MB value, ng/mL & $9.65(4.40-24.60)$ & $46.75(14.35-80.00)$ & 0.065 \\
\hline Left ventricular ejection fraction, $\% \ddagger$ & $35.5(30.0-40.0)$ & $56.0(45.0-64.0)$ & 0.018 \\
\hline Coronary artery disease, $\mathrm{n}(\%)$ & $3(50.0 \%)$ & $24(100 \%)$ & $<0.001$ \\
\hline Systemic arterial hypertension, $\mathrm{n}(\%)$ & $3(50.0 \%)$ & $18(75.0 \%)$ & 0.232 \\
\hline Smoker, n (\%) & $0(0 \%)$ & $2(8.3 \%)$ & 0.208 \\
\hline Diabetes mellitus, n (\%) & $0(0 \%)$ & $8(33.3 \%)$ & 0.099 \\
\hline Dyslipidemia, n (\%) & $5(83.3 \%)$ & $11(45.8 \%)$ & 0.100 \\
\hline Neuropsychiatric disorders, $\mathrm{n}(\%)$ & $3(50.0 \%)$ & $3(12.5 \%)$ & 0.040 \\
\hline
\end{tabular}

number of patients, although inherent to the low prevalence of this condition, limits the drawing of conclusions. On the other hand, our focus on patients suspected of STEMI is a strength of our study. In Brazil, future studies with clinical follow-up that include a large number of patients of this subgroup and analyze data from multicenter registries are necessary to increase the knowledge of TTS.

\section{Conclusions}

The prevalence of TTS among patients initially suspected of STEMI was $3.2 \%$. The clinical profile of TTS differed from that of STEMI in that it was more prevalent in women and was associated with emotional and/or physical stress, neuropsychiatric disorders, lower ejection fraction, lower peak troponin levels, and higher InterTAK scores.

\section{Author contributions}

Conception and design of the research: Costa JPS, Ritt LEF, Campos FAD, Darzé ES. Acquisition of data: Costa JPS, Ritt LEF, Campos FAD, Borges Q, Darzé ES. Analysis and interpretation of the data: Costa JPS, Ritt LEF, Fernandes RM, Campos FAD, Borges Q, Darzé ES. Statistical analysis: Costa JPS, Ritt LEF, Fernandes RM, Borges Q, Darzé ES. Obtaining financing: Costa JPS, Ritt LEF, Borges Q, Darzé ES. Writing of the manuscript: Costa JPS, Ritt LEF, Fernandes RM, Borges Q, Darzé ES. Critical revision of the manuscript for intellectual content: Costa JPS, Ritt LEF, Fernandes RM, Campos FAD, Borges Q, Darzé ES. 


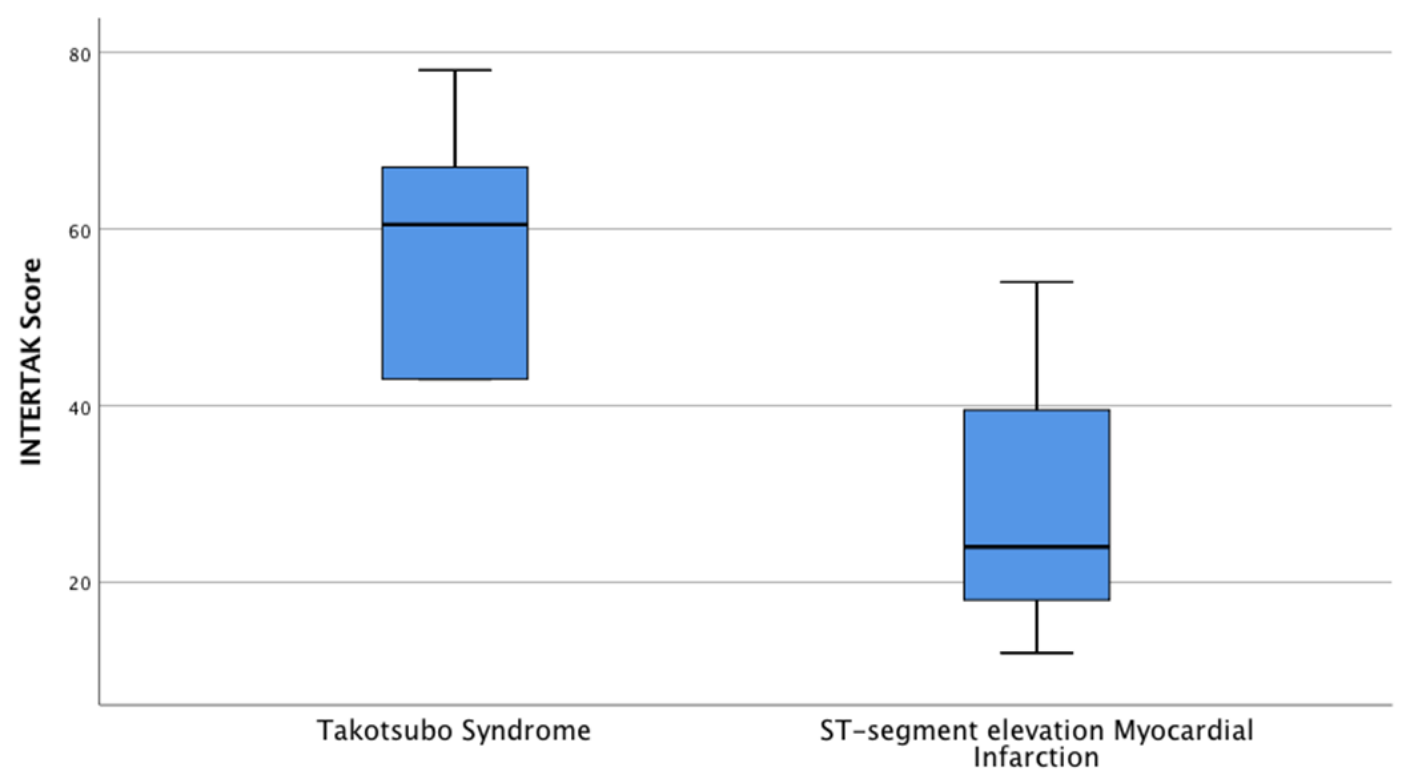

Figure 1 - Comparison of InterTAK scores between patients diagnosed with Takotsubo syndrome and patients diagnosed with STelevation myocardial infarction.

\section{Potential Conflict of Interest}

No potential conflict of interest relevant to this article was reported.

\section{Sources of Funding}

There were no external funding sources for this study.

\section{References}

1. Lyon AR, Bossone E, Schneider B, Sechtem U, Citro R, Underwood SR, et al. Current state of knowledge on Takotsubo syndrome: A Position Statement from the Taskforce on Takotsubo Syndrome of the Heart Failure Association of the European Society of Cardiology. Eur J Heart Fail. 2016;18(1):8-27.

2. Templin C, Ghadri JR, Diekmann J, Napp LC, Bataiosu DR, Jaguszewski $\mathrm{M}$, et al. Clinical Features and Outcomes of Takotsubo (Stress) Cardiomyopathy. N Engl J Med. 2015;373(10):929-38.

3. Ghadri JR, Cammann VL, Jurisic S, Seifert B, Napp LC, Diekmann J, et al. A novel clinical score (InterTAK Diagnostic Score) to differentiate takotsubo syndrome from acute coronary syndrome: results from the International Takotsubo Registry. Eur J Heart Fail. 2016;1(3):335-40.

4. Rodrigues AC, Guimaraes L, Lira E, Oliveira W, Monaco C, Cordovil A, et al. Right Ventricular Abnormalities in Takotsubo Cardiomyopathy. Echocardiography. 2013;30(9):1015-21.

\section{Study Association}

This study is not associated with any thesis or dissertation work.

\section{Ethics approval and consent to participate}

This article does not contain any studies with human participants or animals performed by any of the authors.

5. Prasad A, Lerman A, Rihal CS. Apical ballooning syndrome (Tako-Tsubo or stress cardiomyopathy): A mimic of acute myocardial infarction. Vol. 155, Amer Heart J. 2008;155(3):408-17.

6. Thygesen K, Alpert JS, Jaffe AS, Simoons ML, Chaitman BR, White HD, et al. Third universal definition of myocardial infarction. Circulation. 2012;126(16):2020-35.

7. Ghadri J, Wittstein IS, Prasad A, Sharkey S, Dote K, Akashi YJ, et al International Expert Consensus Document on Takotsubo Syndrome ( Part II ): Diagnostic Workup, Outcome, and Management. Eur Heart J.2018;39(22):2047-62. 